\title{
Therapeutic Hypothermia for Traumatic Brain Injury
}

\author{
L. A. Urbano • Mauro Oddo
}

Published online: 27 July 2012

(C) Springer Science+Business Media, LLC 2012

\begin{abstract}
Experimental evidence demonstrates that therapeutic temperature modulation with the use of mild induced hypothermia (MIH, defined as the maintenance of body temperature at $32-35{ }^{\circ} \mathrm{C}$ ) exerts significant neuroprotection and attenuates secondary cerebral insults after traumatic brain injury (TBI). In adult TBI patients, MIH has been used during the acute "early" phase as prophylactic neuroprotectant and in the sub-acute "late" phase to control brain edema. When used to control brain edema, MIH is effective in reducing elevated intracranial pressure (ICP), and is a valid therapy of refractory intracranial hypertension in TBI patients. Based on the available evidence, we recommend: applying standardized algorithms for the management of induced cooling; paying attention to limit potential side effects (shivering, infections, electrolyte disorders, arrhythmias, reduced cardiac output); and using controlled, slow $\left(0.1-0.2^{\circ} \mathrm{C} / \mathrm{h}\right)$ rewarming, to avoid rebound ICP. The optimal temperature target should be titrated to maintain ICP $<20 \mathrm{mmHg}$ and to avoid temperatures $<35^{\circ}$ C. The duration of cooling should be individualized until the resolution of brain edema, and may be longer than $48 \mathrm{~h}$. Patients with refractory elevated ICP following focal TBI (e.g. hemorrhagic contusions) may respond better to MIH than those with diffuse injury. Randomized controlled trials are underway to evaluate the impact of MIH on neurological outcome in adult TBI patients with elevated ICP. The use of $\mathrm{MIH}$ as prophylactic neuroprotectant in the early phase of
\end{abstract}

L. A. Urbano $\cdot$ M. Oddo $(\bowtie)$

Department of Critical Care Medicine, Lausanne University

Hospital and Faculty of Biology and Medicine, Centre Hospitalier

Universitaire Vaudois (CHUV),

Rue du Bugnon 46,

CH-1011 Lausanne, Switzerland

e-mail: Mauro.Oddo@chuv.ch

L. A. Urbano

e-mail: Luis-Alberto.Urbano@chuv.ch adult TBI is not supported by clinical evidence and is not recommended.

Keywords Head trauma - Traumatic brain injury · Therapeutic hypothermia $\cdot$ Rewarming $\cdot$ Neuroprotection . Intracranial hypertension - Therapeutic temperature modulation

\section{Introduction}

Management of traumatic brain injury (TBI) is aimed to attenuate the amount of so-called secondary brain injury (SBI), i.e. early pathological events (including intracranial hypertension, cerebral hypoxia/ischemia, energy dysfunction, non-convulsive seizures, and systemic insults) that might occur immediately after primary cerebral insult and may add further burden to patient outcome. In the absence of an effective strategy for early neuroprotection, emergent resuscitation and evacuation of surgical lesions, together with the implementation of standardized algorithms for the management of SBI, has considerably reduced mortality and has contributed to improve overall outcome and quality of care [1-4]. Secondary elevations of intracranial pressure (ICP) are frequent in patients with severe TBI and constitute a major determinant of SBI and outcome. Recent studies and meta-analysis have shown increased utilization of ICP monitoring and effective control of elevated ICP burden to be associated with an improvement of outcome after TBI $[5,6]$.

Mild induced hypothermia (MIH, i.e. the induction of therapeutic cooling to a body temperature of $32-35^{\circ} \mathrm{C}$ ) has long been used as a non-pharmacological measure to control secondary elevations of ICP after TBI [3], and may be a valid therapeutic option for refractory elevated ICP [7••], provided adequate management of potential side effects that may occur during both the hypothermic and rewarming phases. 
While MIH may have a place for the management of elevated ICP, its role as an early neuroprotectant is more controversial. A number of animal models have repeatedly demonstrated the benefit [8]. However, the translation of these positive data into clinical human studies has proven difficult, and the benefit of MIH as early neuroprotective strategy after TBI has not been clearly demonstrated, with conflicting data and several negative randomized controlled trials $[9-26 \bullet \bullet]$.

In this review, we will first discuss main neuroprotective properties of $\mathrm{MIH}$ and the potential beneficial effects of MIH in attenuating SBI after TBI. We will then review the role of MIH in the management of SBI in adult TBI patients, with a particular attention to the clinical utility of MIH to treat elevated refractory ICP. We will also review main clinical studies that tested MIH as early neuroprotectant after adult TBI, and conclude with a discussion of the potential optimal utilization of MIH and management of hypothermia-related side effects. Therapeutic temperature modulation for fever control (induced normothermia) will not be addressed.

\section{Mechanisms by Which MIH Attenuates SBI}

MIH attenuates secondary pathological insults following TBI. These pathological processes start minutes to hours after neurotrauma and may continue for up to $72 \mathrm{~h}$ or longer [27]. Therefore, it is important to realize that the therapeutic window of MIH is wide and very much depends on the specific therapeutic aim, and on the time interval between TBI and both the initiation and the duration of therapeutic cooling.

Hypothermic neuroprotection acts at several sites and might exert benefits at different time-points from TBI start (Fig. 1).

Acute "Early" Phase (Minutes to Hours)

\section{Ischemia, Excitotoxicity, Energy Failure, and Cell Death Cascades}

Cerebral ischemia/hypoxia may occur early after TBI, due to direct parenchymal and vascular disruption, acute vasospasm, and post-traumatic vascular stretching and shearing. Nonischemic energy dysfunction, increased glucose utilization and cerebral hyperglycolysis are also frequent and may cause substrate depletion and energy crisis [28, 29]. Excitotoxicity describes the process by which glutamate and others excitatory amino acids cause neuronal damage [30]. Glutamate exposure produces activation of receptors that leads to calcium influx [30]. Increased intracellular calcium concentration activates several proteases, lipases, and endonucleases and increases nitric oxide and oxygen free radicals. This exacerbates mitochondrial damage and DNA alteration, and culminates in necrotic and apoptotic cell death [31] through caspase-independent and caspase-dependent pathways [32].

Effect of MIH:

a. Reduction of Cerebral Metabolic Rate of Oxygen: MIH is known to diminish cerebral metabolic rate of oxygen $\left(\mathrm{CMRO}_{2}\right)$ by approximately $6.5 \% /{ }^{\circ} \mathrm{C}$. MIH decreases cerebral blood flow (CBF) and therefore oxygen delivery; however, energy crisis does not occur because of a matched reduction in oxygen demand, thereby leading to a favorable reduction of oxygen extraction ratio [33].

b. Reduction of Cerebral Glucose Demand: By reducing brain demand for oxygen and glucose, MIH may attenuate post-traumatic cerebral hypoxia/ischemia and energy dysfunction $[34,35]$. MIH also preserves ATP energy stores and maintains tissue $\mathrm{pH}$.

c. Inhibition of Excitotoxicity: A well-known mechanism by which MIH exerts neuroprotection is by reducing calcium influx into the cells and the accumulation and release of excitotoxic amino acids [36, 37••].

d. Reduction in Cerebral Thermopooling: MIH might reduce the gradient of temperature existing between the core of injury and the surrounding tissue, e.g. brain contusions [27].

e. Inhibition of Early Gene Expression and Stress Response: MIH inhibits early molecular cascades involved in the exacerbation of secondary cerebral damage after TBI, particularly by altering the expression of immediate early genes and by suppressing early cellular stress responses [38].

f. Prevention of Apoptotic Death: MIH inhibits apoptosis by modulating gene expression and transcription of factors involved in neuronal apoptosis (e.g. reduction of proapoptotic BAX expression and increase of anti-apoptotic BCL-2 expression), and by inhibiting caspase-dependent and caspase-independent apoptotic pathways [8].

Sub-Acute "Late" Phase (24 Hours to 7 Days)

\section{Brain Edema and Swelling, Blood Brain Barrier Disruption}

After TBI, brain swelling results from both vasogenic and cytotoxic edema [39, 40]. Vasogenic edema results from blood-brain barrier (BBB) disruption leading to an increase in extracellular volume. Furthermore, because of potential impairment of cerebrovascular reactivity, any elevation of mean arterial pressure might translate into increased cerebral blood volume and edema [41]. Cytototoxic or cellular edema may also play a major role [42]. Cellular edema may occur because of a) homeostatic uptake of excitatory amino acids, b) water movement through aquaporins, and c) ionic pump failure [43-45]. 


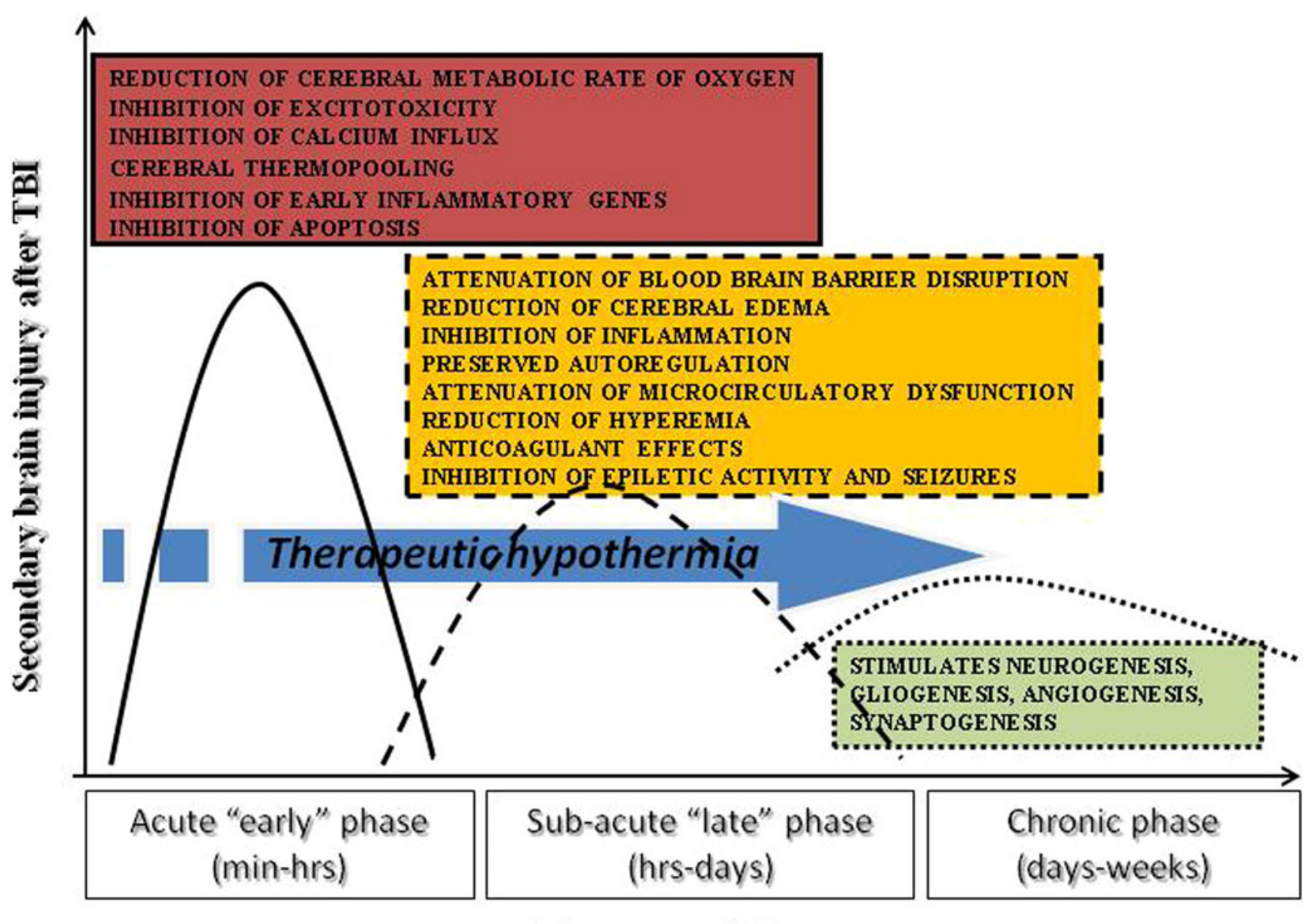

Time from TBI

Fig. 1 Neuroprotective properties of therapeutic hypothermia as a function of time from traumatic brain injury (TBI)

\section{Inflammation}

Cytokines (TNF- $\alpha$, interleukin- $1 \beta$, eicosanoids, neutrophiles, and macrophages) all contribute to post-TBI inflammatory cascades and secondary cerebral damage and repair $[46,47]$. Contusion and local tissue necrosis trigger neutrophil influx, increases in inducible nitric oxide synthase and macrophage infiltration [48]. Macrophage infiltration and the differentiation of endogenous microglia into resident macrophages may signal the link between inflammation and regeneration with elaboration of trophic factors (i.e., nerve growth factor, nitrosothiols, vascular endothelial growth factor) [49, 50]. Studies in animal models suggest early detrimental effects of a number of inflammatory mediators, but beneficial effects of inflammation on long-term outcome [46].

\section{Non-Convulsive Seizures}

Severe TBI is associated with an increased risk of nonconvulsive, clinically subtle or silent seizures [51]. These seizures are associated with increased secondary cerebral damage and tissue loss $[52,53]$.

Effect of MIH:

a. Reduction of BBB Disruption and Limitation of Brain Swelling: At a microcirculatory level, MIH has a major role in reducing $\mathrm{BBB}$ disruption by preserving vascular endothelial function and reducing extracellular protease expression [37••, 54-56]. MIH inhibits micro-thrombus formation induced by brain injury $[57,58]$, the cascade of reactions induced by reperfusion $[8,57,59]$, and the permeability of cellular membranes, with consequent improvement in neuronal function and homeostasis [8, 57]. At a macrocirculatory level, MIH reduces cerebral blood flow and preserves cerebrovascular reactivity [7], thereby minimizing cerebral blood volume and brain swelling. This might explain the effectiveness of $\mathrm{MIH}$ in reducing ICP after TBI [7, 60••] (see below).

b. Inhibition of Inflammation: MIH decreases inflammatory cell infiltration, activation of immune transcription factors and elaboration of damaging free radicals such 
as superoxide, peroxinitrite, hydrogen peroxide, and hydroxyl radicals [61-64].

c. Inhibition of Epileptic Activity and Seizures: MIH attenuates seizure activity $[65,66]$.

\section{Chronic Phase (Weeks to Months)}

\section{Post-Traumatic Axonal Injury}

MIH might modulate the distribution and extension of axonal injury by enhancing neurogenesis [67, 68], gliogenesis, and angiogenesis [68, 69], and by promoting neural outgrowth, neuronal connectivity, and synapse formation [70].

Finally, abundant experimental evidence demonstrates that hypothermic neuroprotection translates into better tissue and neurological recovery (see ref. [37••, 71] for extensive review).

\section{Clinical Utility of MIH}

$\mathrm{MIH}$ has long been suggested as a therapeutic strategy after TBI [72]. Clinical trials evaluating MIH after TBI can be divided into two categories, according to the therapeutic aims:

1. Trials in which MIH was applied in the "late phase" of TBI, to control elevated ICP;

2. Studies in which MIH was applied in the "early phase" of TBI, as prophylactic neuroprotectant.

"Late" MIH for the Management of Elevated ICP in Patients with TBI

Intracranial hypertension - defined as the sustained elevation of ICP above $20-25 \mathrm{mmHg}$ - is frequent in patients with severe TBI and an abnormal CT scan, and is associated with increased mortality and worse functional outcome $[5,6]$. A stepwise approach for the treatment of intracranial hypertension is usually applied. So called first-step therapies consist of treating situations associated with increased cerebral blood volume (seizures, fever, agitation), sedation and neuromuscular blockade, intermittent CSF drainage if available, osmotic fluids (mannitol, hypertonic saline), and controlled moderate hyperventilation. If intracranial hypertension is refractory to these measures and the CT scan does not show surgical treatable lesions, additional so-called second-step therapies are applied. These consist of $\mathrm{MIH}$, barbiturates or decompressive craniectomy.

\section{Effect on ICP}

MIH was tested in severe TBI patients with refractory intracranial hypertension in 17 controlled trials with outcome data
[9-26•]. Compared to normothermia, MIH was associated with significant reduction in elevated ICP in the majority of these studies (Table 1). Furthermore, 12 of these 17 trials reported significant improvements in outcome associated with MIH-related reduction of ICP [9, 11, 13, 14, 17-19, 21-25].

The magnitude of the effect of MIH on ICP reduction was recently reported in a study by Schreckinger et al. in a non-systematic review [7••]. First, the authors analyzed 11 prospective randomized clinical trials that included a total of 367 patients and compared MIH versus normothermia to control elevated ICP after TBI. In all the studies analyzed, MIH was invariably associated with lower ICP than normothermia. In six additional studies, the effect of MIH on ICP reduction was examined: on average, the reduction in ICP obtained by $\mathrm{MIH}$ was $10 \mathrm{mmHg}$ and the decrease varied from 5 $23 \mathrm{mmHg}$. Across the studied analyzed, the effect of MIH on ICP reduction was superior to that achieved with moderate hyperventilation, barbiturates and mannitol $[7 \bullet \bullet]$.

In a recent systematic review by Sadaka et al., the effect of MIH on ICP reduction was further corroborated: among 16 studies comparing MIH to normothermia in TBI patients, all studies found significantly lower ICP in patients treated with MIH (range 10-25 $\mathrm{mmHg}$ ) than in those assigned to normothermia (range $20-35 \mathrm{mmHg}$ ) [6].

These studies suggest that MIH is an effective therapy for intracranial hypertension.

\section{Optimal Target Temperature}

The optimal target temperature of MIH when used for ICP control is not precisely defined. Tokutomi et al. suggest that decreasing body temperature to $35-35.5^{\circ} \mathrm{C}$ effectively treats intracranial hypertension, while maintaining sufficient cerebral perfusion pressure without cardiac dysfunction or oxygen debt [73]. Resting energy expenditure and cardiac output decreased progressively with hypothermia. Oxygen delivery and oxygen consumption decreased to abnormally low levels at rectal temperatures $<35{ }^{\circ} \mathrm{C}$, and the correlation between them became less significant at $<35{ }^{\circ} \mathrm{C}$ than when temperatures were $\geq 35{ }^{\circ} \mathrm{C}$ [73]. Gupta et al. showed MIH below 35 ${ }^{\circ} \mathrm{C}$ decreases brain tissue oxygenation [74]. Thus, 35$35.5{ }^{\circ} \mathrm{C}$ seems to be the optimal temperature at which to treat patients with intracranial hypertension following severe TBI. Instead of applying fixed temperature targets, we suggest that $\mathrm{MIH}$ is targeted on an individual basis, titrating temperature to maintain ICP below $20 \mathrm{mmHg}$. Temperatures $<35{ }^{\circ} \mathrm{C}$ are associated with increased side effects, including cardiac, hemodynamic and infectious complications. 


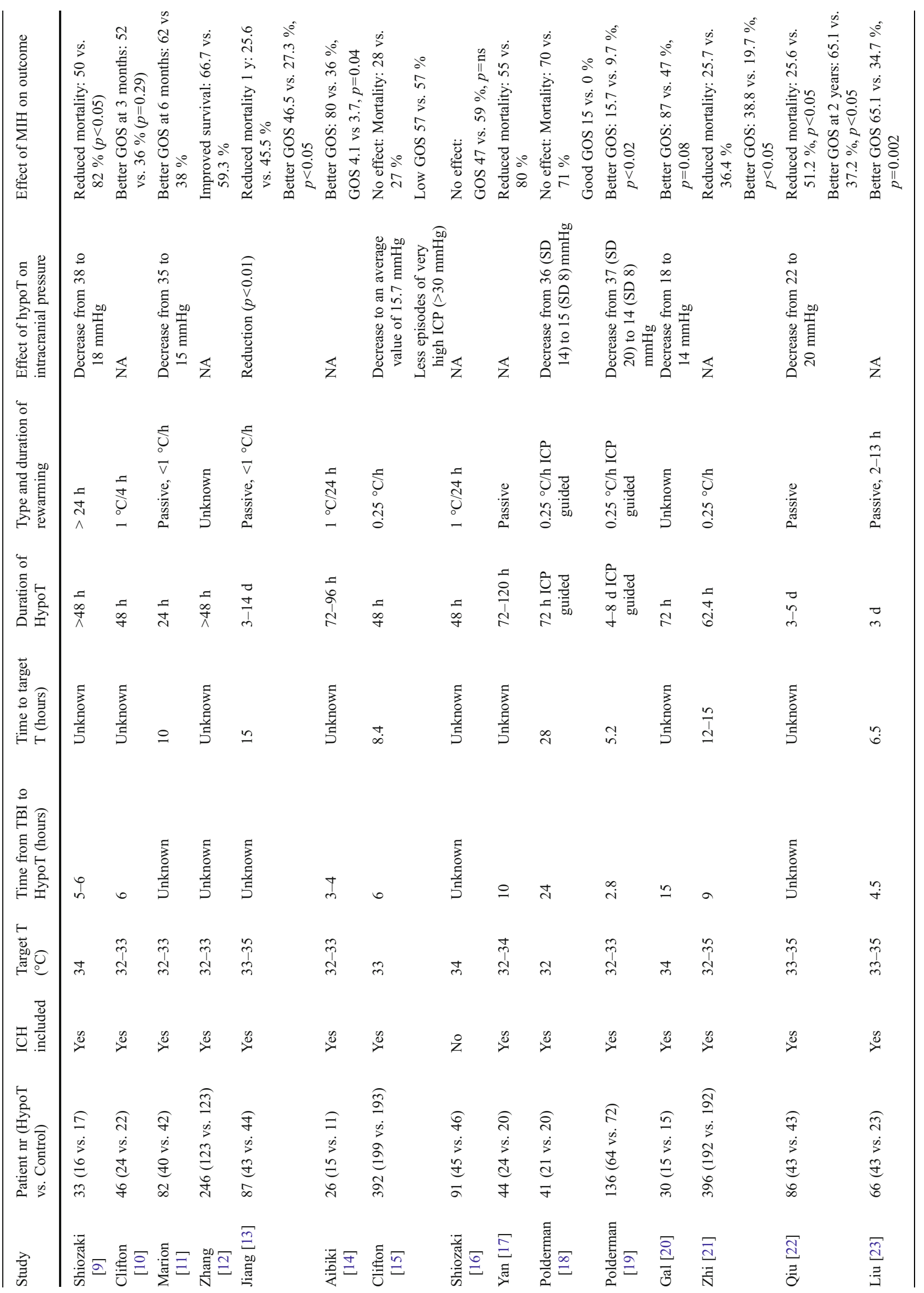


The optimal duration of therapeutic MIH is not known. A meta-analysis by MacIntyre et al. suggested that duration of MIH $>48 \mathrm{~h}$ was associated with better outcomes [75]. Jiang et al. compared "short-term" MIH ( $n=107$ patients, treated for an average of 2 days) to "long-term" MIH ( $n=108$ patients, treated on average for 5 days), and found long-term MIH significantly improved outcome in a group of severe TBI patients with cerebral contusions and intracranial hypertension, without significant complications [76]. Importantly, adverse effects of cooling have been observed principally in the initial phase of MIH, and duration of MIH has not been demonstrated to significantly increase the rate of pneumonia and other complications [15, 19].

\section{Rewarming}

In experimental studies, posttraumatic $\mathrm{MIH}$ followed by slow rewarming provides maximal neurprotective effect, while rapid rewarming not only reverses the protective effects of MIH, but also aggravates post-traumatic induced cerebral damage [77, 78]. The use of uncontrolled rewarming may potentially offset the benefits of $\mathrm{MIH}$, particularly because it may cause rebound intracranial hypertension [10, 11]. Using transcranial Doppler, Iida et al. studied TBI patients treated with MIH who developed acute episodes of elevated ICP and brain swelling during the rewarming phase [79]. Iida et al. demonstrated that hyperemia, evidenced by an increase in middle cerebral artery flow velocities, predicted acute brain swelling associated with rewarming. Lavinio et al. demonstrated that rewarming is associated with a temperature-dependent impairment in cerebrovascular reactivity [80]. A recent study documented episodes of rebound intracranial hypertension during and early after the rewarming phase [26•]. Rapid rewarming was found to correlate with worse outcomes after TBI in a recent study [81].

In conclusion, slow controlled $\left(0.1-0.2^{\circ} \mathrm{C} / \mathrm{h}\right)$ rewarming is recommended after MIH to reduce the risk of rebound cerebral edema and intracranial hypertension [76].

\section{Focal Versus Diffuse Injury}

The type of TBI (contusion vs. diffuse injury) is also a relevant issue: MIH is particularly effective in reducing elevated ICP associated with post-TBI contusions, while patients with elevated ICP secondary to diffuse injury appear to respond less well to hypothermia $[26 \bullet \bullet, 76]$.

Based on the available data, the following can be recommended when applying MIH for the management of refractory elevated ICP: 
- The optimal target temperature should be titrated to maintain ICP below $20-25 \mathrm{mmHg}$, and to around $35^{\circ}$ $\mathrm{C}$; temperatures $<35{ }^{\circ} \mathrm{C}$ may reduce cerebral perfusion pressure and oxygen delivery;

- The optimal duration of MIH depends on the severity of intracranial hypertension; MIH should be individualized and may need to be continued for more than $48 \mathrm{~h}$, and up to $4-5$ days until the peak period of intracranial hypertension (3-5 days) subsides;

- Withdrawal from MIH should be slow, using controlled rewarming $\left(0.1-0.2^{\circ} \mathrm{C} / \mathrm{h}\right)$;

- Patients with refractory elevated ICP following focal TBI (mainly, post-traumatic hemorrhagic contusions) may respond better to MIH than those with diffuse injury.

In summary, MIH is effective in reducing elevated ICP, and is therefore a valid therapeutic option of intracranial hypertension after TBI. Eurotherm3235Trial, an international, multicentre, randomized controlled trial, will examine the effects of $\mathrm{MIH}$ at $32-35{ }^{\circ} \mathrm{C}$ as a treatment for raised intracranial pressure after TBI. Subjects are allowed to be enrolled up to $72 \mathrm{~h}$ after TBI; the duration of cooling is titrated upon the time to control ICP effectively (between 2 and 5 days), and rewarming is used at a rate of $1{ }^{\circ} \mathrm{C}$ per $4 \mathrm{~h}$ [82•].

"Early" MIH as Prophylactic Neuroprotectant in Patients with TBI

Thirteen controlled single-center studies conducted on adult TBI patients demonstrated significantly better outcome associated with MIH [9, 11, 13, 14, 16-19, 21-25]. In contrast, three multicenter randomized controlled trials that tested early (within $10 \mathrm{~h}$ after TBI) "short-term" (max. 48 h) MIH [15, 16, 26•], found no benefit with regards to survival and neurological outcome. The largest trial included 392 patients (199 in the hypothermia group and 193 in the normothermia group)[15]. Outcome at 6 months after TBI was not significantly different in the two groups (relative risk of poor outcome $1,95 \%$ CI $0.8-1.2, p=0.99$ ). Internal validity of this trial was lowered by inter-center variability in the management of induced hypothermia, age of subjects, severity of illness scoring, and the management of cerebral perfusion pressures and hemodynamics [83]. Lesser expertise with the management of MIH was associated with more complications.

Given the discrepancy between single center and multicenter trials, many meta-analyses have attempted to further examine the impact of prophylactic MIH on outcome after TBI [76, 84-92]. Four of these metaanalyses have been published as Cochrane systematic reviews [88-91•]. Sydenham et al. included 21 trials with outcome data involving 1,587 subjects [91•]: mortality was not significantly different in patients treated with MIH vs. normothermia (OR 0.85, $95 \%$ CI 0.68 1.06), but MIH was associated with a lower rate of unfavorable outcome (OR 0.77, $95 \%$ CI 0.62-0.94). When limiting the analysis to high quality RCT, i.e. to the nine studies with good allocation concealment, mortality and unfavorable outcome did not differ between the two groups. The efficacy of early MIH in reducing death and unfavorable outcome was only found in low quality trials, which overestimate the treatment effect [91•]. Data from recent meta-analyses on the effect of MIH used as early neuroprotectant are summarized in Fig. 2.

Finally, Clifton et al. recently published the National Acute Brain Injury Study: Hypothermia II (NABIS: H II), a multicentre RCT including patients who were 1645 years old after severe, non-penetrating TBI, treated with $\mathrm{MIH}$ [26•]. The trial was stopped after inclusion of 108 patients, and no effect on outcome was seen (relative risk of poor outcome of MIH vs. normothermia $1.08,95 \%$ CI $0.76-1.53 ; p=0.67)$. Subgroup analysis found that patients with surgically evacuated hematomas treated with MIH had better outcome than those assigned to normothermia $(p=0.02)$, while those with diffuse brain injury treated with hypothermia had a trend to poorer outcome $(p=0.09)$. Although not conclusive, these data suggest different effects of MIH depending on the type of TBI. Moreover, one-third of surgically treated patients in the hypothermia group had decompressive craniectomies, which itself may have suppressed rebound intracranial hypertension [26•]. This again raises the difficulty of including heterogeneous patients with TBI in clinical trials [93].

\section{Management of Side Effects of MIH}

\section{Temperature-Related}

Shivering MIH may cause shivering, which in turn might increase oxygen consumption and energy expenditure [94], and reduce brain tissue oxygenation [95]. Recognition of shivering is mandatory and can be achieved by using ad hoc scales [96]. Therapies of shivering include increased sedation (propofol) and analgesia (fentanyl), meperidine, dexmedetomidine, buspirone [97].

Infections $\mathrm{MIH}$ is associated with increased infections $[60 \bullet, 98]$. Careful surveillance of infections is mandatory, and includes regular microbiological sampling and followup of infection biomarkers such as procalcitonin. Infection 


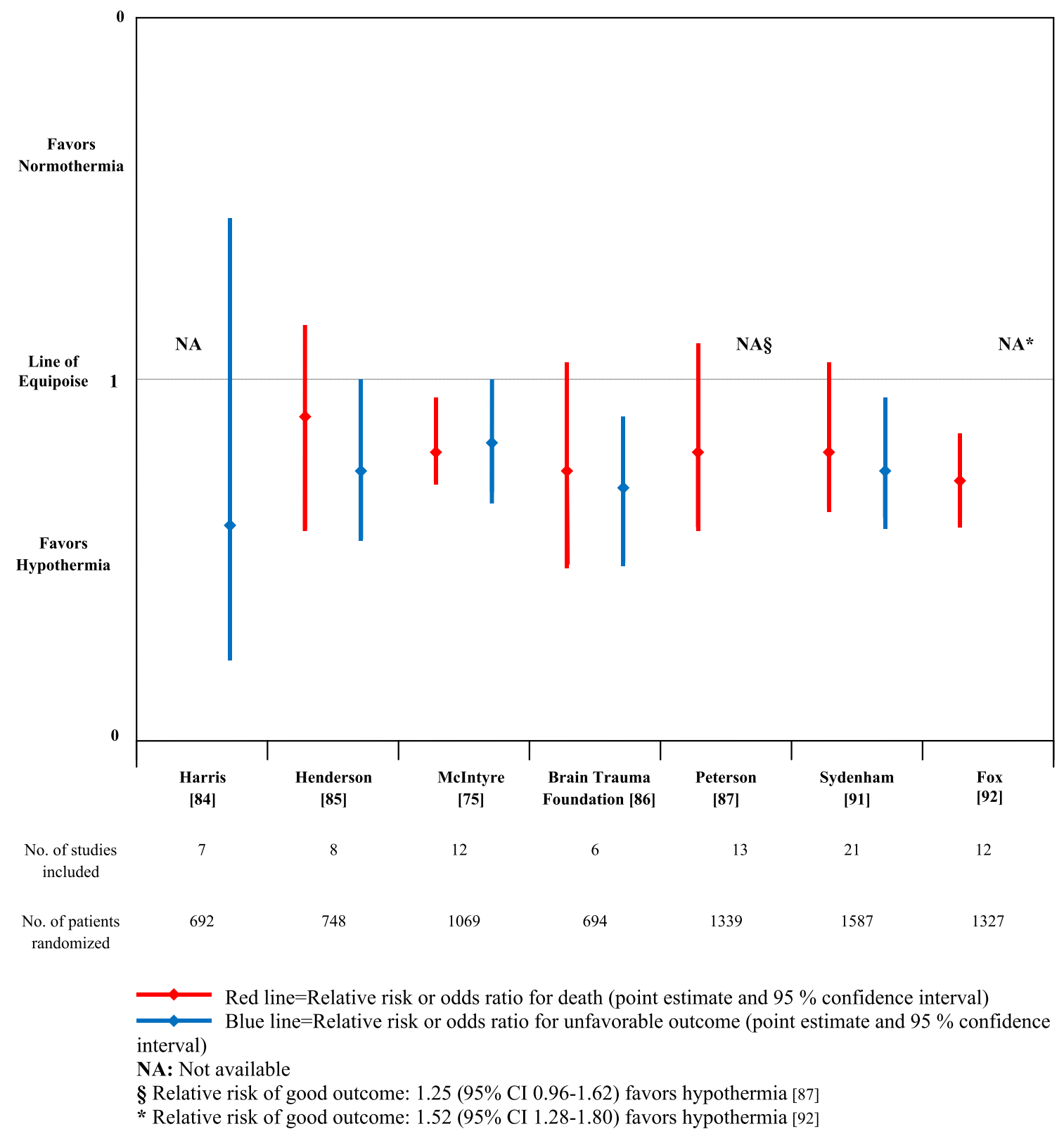

Fig. 2 Summary of recent meta-analyses that evaluated the effect of mild induced hypothermia versus normothermia on the outcome (mortality, in red and proportion with poor outcome, in blue) in adult severe TBI patients

prevention, like the use of selective digestive decontamination, may reduce the infection risk related to MIH [99].

Cardiovascular MIH is associated with reduced heart rate and cardiac output, which are usually well tolerated. Arrhythmias are associated with hypokalemia, generally during the rewarming phase $[60 \bullet \bullet$, and must be prevented by close monitoring of potassium levels.

Hemorrhage Despite prolonged partial thromboplastin time (PTT) and thrombocytopenia having been reported during MIH [60••], no study has documented an increased risk of bleeding.

\section{Technique-Related}

Skin Injury Surface cooling devices have been associated with skin lesions.

Thrombosis Using intravascular devices for MIH may be associated with vascular (venous) thrombosis, particularly when MIH is maintained for more than 48-72 $\mathrm{h}$ [100]. When using prolonged surface cooling, we also recommend carefully monitoring patients for potential skin injuries.

Development of local standardized algorithms for the management of MIH is recommended, and may help reduce 
side effects of MIH and increase the potential benefit of the therapy [84].

\section{Conclusion}

Therapeutic hypothermia has many neuroprotective effects that may all contribute to reduce secondary cerebral damage after traumatic brain injury. In clinical practice, therapeutic hypothermia has been used in the early phase of traumatic brain injury, as prophylactic neurprotectant, and in the late phase, to control brain edema and elevated intracranial pressure.

Mild induced hypothermia to $32-35{ }^{\circ} \mathrm{C}$ is effective in reducing elevated intracranial pressure and is a valid therapeutic. Based on the available clinical evidence, we recommend the development and application of local standardized algorithms for the management of induced cooling. These should pay particular attention to limiting side effects (shivering, infections, electrolyte disorders, arrhythmias, reduced cardiac output) and to the use of controlled, slow $\left(0.1-0.2{ }^{\circ} \mathrm{C} / \mathrm{h}\right)$ rewarming. The optimal temperature target should be titrated to maintain ICP below $20-25 \mathrm{mmHg}$ and as much as possible to avoid body temperature $<35{ }^{\circ} \mathrm{C}$. The duration of cooling should be individualized and may need to be maintained for longer than $48 \mathrm{~h}$, until the resolution of brain edema and intracranial hypertension. Patients with refractory elevated ICP following focal TBI (hemorrhagic contusions) may respond better to mild induced hypothermia than those with diffuse injury. Randomized controlled trials that evaluate the impact on outcome of mild induced hypothermia in adult traumatic brain injury patients with elevated intracranial pressure are underway.

In contrast, based on the available evidence, we do not recommend the use of mild induced hypothermia as prophylactic neuroprotectant in the early phase of traumatic brain injury.

Acknowledgements Mauro Oddo is supported by a grant form the Swiss National Science Foundation (grant nr. 320030 138191).

Disclosure No potential conflicts of interest relevant to this article were reported.

\section{References}

Papers of particular interest, published recently, have been highlighted as:

- Of importance,

.- Of major importance

1. Lu J, Marmarou A, Choi S, et al. Mortality from traumatic brain injury. Acta Neurochir Suppl. 2005;95:281-5.
2. Elf K, Nilsson P, Enblad P. Outcome after traumatic brain injury improved by an organized secondary insult program and standardized neurointensive care. Crit Care Med. 2002;30:2129-34.

3. Brain Trauma Foundation; American Association of Neurological Surgeons; Congress of Neurological Surgeons. Guidelines for the management of severe traumatic brain injury. $\mathrm{J}$ Neurotrauma. 2007;24 Suppl 1:S1-106. Erratum in: J Neurotrauma 2008,25:276-278.

4. Suarez JI. Outcome in neurocritical care: advances in monitoring and treatment and effect of a specialized neurocritical care team. Crit Care Med. 2006;34(9 Suppl):S232-238.

5. Treggiari MM, Schutz N, Yanez ND, Romand JA. Role of intracranial pressure values and patterns in predicting outcome in traumatic brain injury: a systematic review. Neurocrit Care. 2007;6:104-12.

6. Stein SC, Georgoff P, Meghan S, et al. Relationship of aggressive monitoring and treatment to improved outcomes in severe traumatic brain injury. J Neurosurg. 2010;112:1105-12.

7. •- Schreckinger M, Marion DW: Contemporary management of traumatic intracranial hypertension: is there a role for therapeutic hypothermia? Neurocrit Care 2009, 11:427-436. This is an important non-systematic review that quantifies, across several clinical studies, the effect of moderate induced hypothermia to treat intracranial hypertension in adult TBI patients, and compared its efficacy to other commonly used therapies for raised intracranial pressure, such as moderate hyperventilation, osmotic therapy, barbiturates.

8. Liu L, Yenari MA. Therapeutic hypothermia: neuroprotective mechanisms. Front Biosci. 2007;12:816-25.

9. Shiozaki T, Sugimoto H, Taneda M, et al. Effect of mild hypothermia on uncontrollable intracranial hypertension after severe head injury. J Neurosurg. 1993;79:363-8.

10. Clifton GL, Allen S, Barrodale P, et al. A phase II study of moderate hypothermia in severe brain injury. J Neurotrauma. 1993;10:263-71.

11. Marion DW, Penrod LE, Kelsey SF, et al. Treatment of traumatic brain injury with moderate hypothermia. $\mathrm{N}$ Engl J Med. 1997;336:540-6.

12. Zhang K, Wang JX. Comparative study on mild hypothermia in patients with severe head injury and the most severe head injury. Inner Mongol Med J. 2000;32:4-6.

13. Jiang J, Yu M, Zhu C. Effect of long-term mild hypothermia therapy in patients with severe traumatic brain injury: 1-year follow-up review of 87 cases. J Neurosurg. 2000;93:546-9.

14. Aibiki M, Maekawa S, Yokono S. Moderate hypothermia improves imbalances of thromboxane A2 and prostaglandin I2 production after traumatic brain injury in humans. Crit Care Med. 2000;28:3902-6.

15. Clifton GL, Miller ER, Choi SC, et al. Lack of effect of induction of hypothermia after acute brain injury. N Engl J Med. 2001;344:556-63.

16. Shiozaki T, Hayakata T, Taneda M, et al. A multicenter prospective randomized controlled trial of the efficacy of mild hypothermia for severely head injured patients with low intracranial pressure. Mild Hypothermia Study Group in Japan. J Neurosurg. 2001;94:50-4.

17. Yan Y, Tang W. Changes of evoked potentials and evaluation of mild hypothermia for treatment of severe brain injury. Chin $\mathrm{J}$ Traumatol. 2001;4:8-13.

18. Polderman KH, Peerdeman SM, Girbes AR. Hypophosphatemia and hypomagnesemia induced by cooling in patients with severe head injury. J Neurosurg. 2001;94:697-705.

19. Polderman KH, Tjong Tjin Joe R, Peerdeman SM, et al. Effects of therapeutic hypothermia on intracranial pressure and outcome in patients with severe head injury. Intensive Care Med. 2002;28:1563-73. 
20. Gal R, Cundrle I, Zimova I, Smrcka M. Mild hypothermia therapy for patients with severe brain injury. Clin Neurol Neurosurg. 2002;104:318-21.

21. Zhi D, Zhang S, Lin X. Study on therapeutic mechanism and clinical effect of mild hypothermia in patients with severe head injury. Surg Neurol. 2003;59:381-5.

22. Qiu WS, Liu WG, Shen H, et al. Therapeutic effect of mild hypothermia on severe traumatic head injury. Chin J Traumatol. $2005 ; 8: 27-32$.

23. Liu WG, Qiu WS, Zhang Y, et al. Effects of selective brain cooling in patients with severe traumatic brain injury: a preliminary study. J Int Med Res. 2006;34:58-64.

24. Qiu W, Shen H, Zhang Y, et al. Noninvasive selective brain cooling by head and neck cooling is protective in severe traumatic brain injury. J Clin Neurosci. 2006;13:995-1000.

25. Qiu W, Zhang Y, Sheng H, et al. Effects of therapeutic mild hypothermia on patients with severe traumatic brain injury after craniotomy. J Crit Care. 2007;22:229-36.

26. • Clifton GL, Valadka A, Zygun D, et al.: Very early hypothermia induction in patients with severe brain injury (the National Acute Brain Injury Study: Hypothermia II): a randomised trial. Lancet Neurol 2011, 10:131-139. This recent multicenter randomized control trial that evaluated the effect of mild induced hypothermia as early neuroprotectant was stopped because of lack of effect. Additional negative data that do not support the use of hypothermia in the early phase of TBI. This study suggests hypothermia may be more beneficial in patients with focal vs. diffuse TBI.

27. Polderman KH. Therapeutic hypothermia in the intensive care unit: problems, pitfalls and opportunities (review). Part 1: indications and evidence. Intensive Care Med. 2004;30:556-75.

28. Vespa P, Bergsneider M, Hattori N, et al. Metabolic crisis without brain ischemia is common after traumatic brain injury: a combined microdialysis and positron emission tomography study. J Cereb Blood Flow Metab. 2005;25:763-74.

29. Glenn TC, Kelly DF, Boscardin WJ, et al. Energy dysfunction as a predictor of outcome after moderate or severe head injury: indices of oxygen, glucose, and lactate metabolism. J Cereb Blood Flow Metab. 2003;23:1239-50.

30. Nilsson P, Laursen H, Hillered L, Hansen AJ. Calcium movements in traumatic brain injury: the role of glutamate receptor-operated ion channels. J Cereb Blood Flow Metab. 1996;16:262-70.

31. Moquin D, Chan FK. The molecular regulation of programmed necrotic cell injury. Trends Biochem Sci. 2010;35:434-41.

32. Ashkenazi A, Dixit VM. Death receptors: signaling and modulation. Science. 1998;281:1305-8.

33. Bacher A, Illievich UM, Fitzgerald R, et al. Changes in oxygenation variables during progressive hypothermia in anesthetized patients. J Neurosurg Anesthesiol. 1997;9:205-10.

34. Soukup J, Zauner A, Doppenberg EM, Menzel M, et al. Relationship between brain temperature, brain chemistry and oxygen delivery after severe human head injury: the effect of mild hypothermia. Neurol Res. 2002;24:161-8.

35. Oddo M, Frangos S, Milby A, et al. Induced normothermia attenuates cerebral metabolic distress in patients with aneurysmal subarachnoid hemorrhage and refractory fever. Stroke. 2009;40:1913-6.

36. Colbourne F, Grooms SY, Zukin RS, et al. Hypothermia rescues hippocampal CA1 neurons and attenuates down-regulation of the AMPA receptor GluR2 subunit after forebrain ischemia. Proc Natl Acad Sci USA. 2003;100:2906-10.

37. •• Dietrich WD, Bramlett HM: The evidence for hypothermia as a neuroprotectant in traumatic brain injury. Neurotherapeutics 2010, 7:43-50. An extensive review of all mechanisms by which mild induced hypothermia exerts neuroprotection and of experimental and clinical evidence in favor of hypothermic therapy after traumatic brain injury.
38. Truettner JS, Alonso OF, Bramlett HM, Dietrich WD. Therapeutic hypothermia alters microRNA responses to traumatic brain injury in rats. J Cereb Blood Flow Metab. 2011;31:1897-907.

39. Marmarou A. A review of progress in understanding the pathophysiology and treatment of brain edema. Neurosurg Focus. 2007;22:1-10.

40. Unterberg AW, Stover J, Kress B, Kiening KL. Edema and brain trauma. Neuroscience. 2004;129:1021-9.

41. Lang EW, Lagopoulos J, Griffith J, et al. Cerebral vasomotor reactivity testing in head injury: the link between pressure and flow. J Neurol Neurosurg Psychiatry. 2003;74:1053-9.

42. Marmarou A, Signoretti S, Fatouros PP, et al. Predominance of cellular edema in traumatic brain swelling in patients with severe head injuries. J Neurosurg. 2006;104:720-30.

43. Nag S, Manias JL, Stewart DJ. Pathology and new players in the pathogenesis of brain edema. Acta Neuropathol. 2009;118:197217.

44. Sun MC, Honey CR, Berk C, et al. Regulation of aquaporin-4 in a traumatic brain injury model in rats. J Neurosurg. 2003;98:565-9.

45. Katayama Y, Kawamata T. Edema fluid accumulation within necrotic brain tissue as a cause of the mass effect of cerebral contusion in head trauma patients. Acta Neurochir Suppl. 2003;86:323-7.

46. Scherbel U, Raghupathi R, Nakamura M, et al. Differential acute and chronic responses of tumor necrosis factordeficient mice to experimental brain injury. Proc Natl Acad Sci U S A. 1999;96:8721-6.

47. Toulmond S, Rothwell NJ. Interleukin-1 receptor antagonist inhibits neuronal damage caused by fluid percussion injury in the rat. Brain Res. 1995;671:261-6.

48. Forster C, Clark HB, Ross ME, Iadecola C. Inducible nitric oxide synthase expression in human cerebral infarcts. Acta Neuropathol. 1999;97:215-20.

49. Bayir H, Kochanek PM, Liu SX, et al. Increased Snitrosothiols and S-nitrosoalbumin in cerebrospinal fluid after severe traumatic brain injury in infants and children: indirect association with intracranial pressure. J Cereb Blood Flow Metab. 2003;23:51-61.

50. Shore PM, Jackson EK, Wisniewski SR, et al. Vascular endothelial growth factor is increased in cerebrospinal fluid after traumatic brain injury in infants and children. Neurosurgery. 2004;54:605-11.

51. Rossetti AO, Oddo M. The neuro-ICU patient and electroencephalography paroxysms: if and when to treat. Curr Opin Crit Care. 2010;16:105-9.

52. Vespa PM, Miller C, McArthur D, et al. Nonconvulsive electrographic seizures after traumatic brain injury result in a delayed, prolonged increase in intracranial pressure and metabolic crisis. Crit Care Med. 2007;35:2830-6.

53. Vespa PM, McArthur DL, Xu Y, et al. Nonconvulsive seizures after traumatic brain injury are associated with hippocampal atrophy. Neurology. 2010;75:792-8.

54. Truettner JS, Alonso OF. Dalton Dietrich, W. Influence of therapeutic hypothermia on matrix metalloproteinase activity after traumatic brain injury in rats. J Cereb Blood Flow Metab. 2005;25:1505-16.

55. Oda Y, Gao G, Wei EP, Povlishock JT. Combinational therapy using hypothermia and the immunophilin ligand FK506 to target altered pial arteriolar reactivity, axonal damage, and blood-brain barrier dysfunction after traumatic brain injury in rat. $\mathrm{J}$ Cereb Blood Flow Metab. 2011;31:1143-54.

56. Lotocki G, de Rivero Vaccari JP, Perez ER, et al. Alterations in blood-brain barrier permeability to large and small molecules and leukocyte accumulation after traumatic brain injury: effects of post-traumatic hypothermia. J Neurotrauma. 2009;26:1123-34. 
57. Polderman KH. Induced hypothermia and fever control for prevention and treatment of neurological injuries. Lancet. 2008;371:1955-69.

58. Martini WZ. Coagulopathy by hypothermia and acidosis: mechanisms of thrombin generation and fibrinogen availability. J Trauma. 2009;67:202-9.

59. Nagel S, Su Y, Horstmann S, et al. Minocycline and hypothermia for reperfusion injury after focal cerebral ischemia in the rat: effects on BBB breakdown and MMP expression in the acute and subacute phase. Brain Res. 2008;1188:198-206.

60. •- Sadaka F, Veremakis C: Therapeutic hypothermia for the management of intracranial hypertension in severe traumatic brain injury: a systematic review. Brain Inj. 2012, Mar 26. Epub ahead of print. A systematic review that examines the efficacy and clinical utility of mild induced hypothermia for the treatment of intracranial hypertension in TBI patients.

61. Deng H, Han HS, Cheng D, et al. Mild hypothermia inhibits inflammation after experimental stroke and brain inflammation. Stroke. 2003;34:2495-501.

62. Truettner JS, Suzuki T, Dietrich WD. The effect of therapeutic hypothermia on the expression of inflammatory response genes following moderate traumatic brain injury in the rat. Brain Res Mol Brain Res. 2005;138:124-34.

63. Yenari MA, Han HS. Influence of hypothermia on post-ischemic inflammation: role of nuclear factor kappa B (NFKB). Neurochem Int. 2006;49:164-9.

64. Sahuquillo J, Vilalta A. Cooling the injured brain: how does moderate hypothermia influence the pathophysiology of traumatic brain injury. Curr Pharm Des. 2007;13:2310-22.

65. Karkar KM, Garcia PA, Bateman LM, et al. Focal cooling suppresses spontaneous epileptiform activity without changing the cortical motor threshold. Epilepsia. 2002;43:932-5.

66. Atkins CM, Truettner JS, Lotocki G, et al. Post-traumatic seizure susceptibility is attenuated by hypothermia therapy. Eur J Neurosci. 2010;32:1912-20.

67. Kernie SG, Parent JM. Forebrain neurogenesis after focal ischemic and traumatic brain injury. Neurobiol Dis. 2010;37:267-74.

68. Kuo JR, Lo CJ, Chang CP, et al. Brain cooling-stimulated angiogenesis and neurogenesis attenuated traumatic brain injury in rats. J Trauma. 2010;69:1467-72.

69. Lotocki G, de Rivero Vaccari J, Alonso O, et al.: Oligodendrocyte vulnerability following traumatic brain injury in rats: effect of moderate hypothermia. Therapeutic Hypothermia and Temperature Management 2011, 1:43-51.

70. Feng JF, Zhang KM, Jiang JY, et al. Effect of therapeutic mild hypothermia on the genomics of the hippocampus after moderate traumatic brain injury in rats. Neurosurgery. 2010;67:730-42.

71. Dietrich WD, Atkins CM, Bramlett HM. Protection in animal models of brain and spinal cord injury with mild to moderate hypothermia. J Neurotrauma. 2009;26:301-12.

72. Fay T. Observations on generalizated refrigeration in cases of severe cerebral trauma. Assoc Res Nerv Ment Dis Proc. 1945;24:611-9.

73. Tokutomi T, Morimoto K, Miyagi T, et al. Optimal temperature for the management of severe traumatic brain injury: effect of hypothermia on intracranial pressure, systemic and intracranial hemodynamics, and metabolism. Neurosurgery. 2007;61(1 Suppl):256-65.

74. Gupta AK, Al-Rawi PG, Hutchinson PJ, Kirkpatrick PJ. Effect of hypothermia on brain tissue oxygenation in patients with severe head injury. Br J Anaesth. 2002;88:188-92.

75. McIntyre LA, Fergusson DA, Hebert PC, et al. Prolonged therapeutic hypothermia after traumatic brain injury in adults: a systematic review. JAMA. 2003;289:2992-9.

76. Jiang JY, Xu W, Li WP, et al. Effect of long-term mild hypothermia or short-term mild hypothermia on outcome of patients with severe traumatic brain injury. J Cereb Blood Flow Metab. 2006;26:771-6.

77. Suehiro E, Povlishock JT. Exacerbation of traumatically induced axonal injury by rapid posthypothermic rewarming and attenuation of axonal change by cyclosporine A. J Neurosurg. 2001;94:493-8.

78. Suehiro E, Ueda Y, Wei EP, et al. Posttraumatic hypothermia followed by slow rewarming protects the cerebral microcirculation. J Neurotrauma. 2003;20:381-90.

79. Iida K, Kurisu K, Arita K, Ohtani M. Hyperemia prior to acute brain swelling during rewarming of patients who have been treated with moderate hypothermia for severe head injuries. J Neurosurg. 2003;98:793-9.

80. Lavinio A, Timofeev I, Nortje J, et al. Cerebrovascular reactivity during hypothermia and rewarming. Br J Anaesth. 2007;99:23744.

81. Thompson HJ, Kirkness CJ, Mitchell PH. Hypothermia and rapid rewarming is associated with worse outcome following traumatic brain injury. J Trauma Nurs. 2010;17:173-7.

82. - Andrews PJ, Sinclair HL, Battison CG, et al.: European society of intensive care medicine study of therapeutic hypothermia (32$35^{\circ} \mathrm{C}$ ) for intracranial pressure reduction after traumatic brain injury (the Eurotherm3235Trial). Trials 2011, 12:8. This article reviews the study protocol of an ongoing multi-centre randomized controlled trial examining the effects of hypothermia - titrated to reduce intracranial pressure - on morbidity and mortality 6 months after traumatic brain injury.

83. Clifton GL, Choi SC, Miller ER, et al. Intercenter variance in clinical trials of head trauma-experience of the National Acute Brain Injury Study: hypothermia. J Neurosurg. 2001;95:751-5.

84. Harris OA, Colford Jr JM, Good MC, Matz PG. The role of hypothermia in the management of severe brain injury: a metaanalysis. Arch Neurol. 2002;59:1077-83.

85. Henderson WR, Dhingra VK, Chittock DR, et al. Hypothermia in the management of traumatic brain injury. A systematic review and meta-analysis. Intensive Care Med. 2003;29:1637-44.

86. Brain Trauma Foundation; American Association of Neurological Surgeons; Congress of Neurological Surgeons; Joint Section on Neurotrauma and Critical Care, AANS/CNS. Guidelines for the management of severe traumatic brain injury. III. Prophylactic hypothermia. J Neurotrauma. 2007;24 suppl 1:21-5.

87. Peterson K, Carson S, Carney N. Hypothermia treatment for traumatic brain injury: a systematic review and meta-analysis. J Neurotrauma. 2008;25:62-71.

88. Signorini DF, Alderson P. Therapeutic hypothermia for head injury. Cochrane Database Syst Rev. 2000;2:CD001048.

89. Gadkary CS, Alderson P, Signorini DF. Therapeutic hypothermia for head injury. Cochrane Database Syst Rev. 2002;1:CD001048.

90. Alderson P, Gadkary C, Signorini DF. Therapeutic hypothermia for head injury. Cochrane Database Syst Rev. 2004;4:CD001048.

91. - Sydenham E, Roberts I, Alderson P: Hypothermia for traumatic head injury. Cochrane Database Syst Rev 2009, 2:CD001048. The latest meta-analysis of the Cochrane Collaboration evaluating post-traumatic prophylactic hypothermia, and including 22 randomized controlled trials and 1587 patients.

92. Fox JL, Vu EN, Doyle-Waters M, et al. Prophylactic hypothermia for traumatic brain injury: a quantitative systematic review. CJEM. 2010;22:355-64.

93. Maas A, Stocchetti N. Hypothermia and the complexity of trials in patients with traumatic brain injury. Lancet Neurol. 2011;10:111-3.

94. Badjatia N, Strongilis E, Gordon E, et al. Metabolic impact of shivering during therapeutic temperature modulation: the Bedside Shivering Assessment Scale. Stroke. 2008;39:3242-7. 
95. Oddo M, Frangos S, Maloney-Wilensky E, et al. Effect of shivering on brain tissue oxygenation during induced normothermia in patients with severe brain injury. Neurocrit Care. 2010;12:10-6.

96. Choi HA, Ko SB, Presciutti M, et al. Prevention of shivering during therapeutic temperature modulation: the Columbia antishivering protocol. Neurocrit Care. 2011;14:389-94.

97. Choi HA, Badjatia N, Mayer SA. Hypothermia for acute brain injury-mechanisms and practical aspects. Nat Rev Neurol. 2012;8:214-22.
98. Mongardon N, Perbet S, Lemiale V, et al. Infectious complications in out-of-hospital cardiac arrest patients in the therapeutic hypothermia era. Crit Care Med. 2011;39:1359-64.

99. Kamps M, Bisschops LA, van der Hoeven JG, Hoedemaekers CW. Hypothermia does not increase the risk of infection: a case control study. Crit Care. 2011;15:R48.

100. Simosa HF, Petersen DJ, Agarwal SK, et al. Increased risk of deep venous thrombosis with endovascular cooling in patients with traumatic head injury. Am Surg. 2007;73:461-4. 